\title{
Ultra-endurance sports have no negative impact on indices of arterial stiffness
}

\author{
Thomas Radtke $\cdot$ Arno Schmidt-Trucksäss • \\ Nicolas Brugger · Daniela Schäfer · Hugo Saner • \\ Matthias Wilhelm
}

Received: 13 August 2013 / Accepted: 10 October 2013 / Published online: 19 October 2013

(C) Springer-Verlag Berlin Heidelberg 2013

\begin{abstract}
Purpose Marathon running has been linked with higher arterial stiffness. Blood pressure is a major contributor to pulse wave velocity (PWV). We examined indices of arterial stiffness with a blood pressure-independent method in marathon runners and ultra-endurance athletes.

Methods Male normotensive amateur runners were allocated to three groups according to former participation in competitions: group I (recreational athletes), group II (marathon runners) and group III (ultra-endurance athletes). Indices of arterial stiffness were measured with a non-invasive device (VaSera VS-1500N, Fukuda Denshi, Japan) to determine the cardio-ankle vascular index (CAVI, primary endpoint) and brachial-ankle PWV (baPWV). Lifetime training hours were calculated. Cumulative competitions were expressed as marathon equivalents. Linear regression analysis was performed to determine predictors for CAVI and baPWV.

Results Measurements of arterial stiffness were performed in 51 subjects (mean age $44.6 \pm 1.2$ years): group I $(n=16)$, group II $(n=19)$ and group III $(n=16)$. No between-group differences existed in age, anthropometric characteristics and resting $\mathrm{BP}$. CAVI and baPWV were comparable between all groups $(P=0.604$ and $P=0.947$,
\end{abstract}

Communicated by David C. Poole.

T. Radtke $\cdot$ N. Brugger $\cdot$ D. Schäfer $\cdot$ H. Saner $\cdot$ M. Wilhelm $(\bowtie)$ Division of Cardiovascular Prevention, Rehabilitation and Sports Medicine, Swiss Cardiovascular Center, Inselspital, University Hospital and University of Bern, 3010 Bern, Switzerland e-mail: matthias.wilhelm@insel.ch

A. Schmidt-Trucksäss

Division of Sports and Exercise Medicine, Institute of Exercise and Health Sciences, University of Basel, Basel, Switzerland respectively). In linear regression analysis, age was the only independent predictor for CAVI $\left(R^{2}=0.239, \beta=0.455\right.$, $P=0.001)$. Systolic BP was significantly associated with baPWV $\left(R^{2}=0.225, \beta=0.403, P=0.004\right)$.

Conclusions In middle-aged normotensive athletes marathon running and ultra-endurance sports had no negative impact on arterial stiffness.

Keywords Cardiovascular remodeling - Marathon running $\cdot$ Normotensive $\cdot$ Atherosclerosis $\cdot$ Pulse wave velocity

$\begin{array}{ll}\text { Abbreviations } \\ \text { A-wave } & \text { Late diastolic filling velocity } \\ \text { baPWV } & \text { Brachial-ankle pulse wave velocity } \\ \text { BMI } & \text { Body mass index } \\ \text { BP } & \text { Blood pressure } \\ \text { CAVI } & \text { Cardio-ankle vascular index } \\ \text { CV } & \text { Cardiovascular } \\ e^{\prime} & \text { Peak septal mitral annular velocity } \\ \text { E-wave } & \text { Peak early filling velocity } \\ \text { LV } & \text { Left ventricular } \\ \text { PWV } & \text { Pulse wave velocity }\end{array}$

\section{Introduction}

The benefits of regular physical activity on atherosclerotic disease and cardiovascular (CV) mortality have been well established in humans (Thompson et al. 2003). There is an ongoing debate on adverse $\mathrm{CV}$ health effects of chronic extreme exercise in humans (O'Keefe and Lavie 2013; O'Keefe et al. 2012, 2013) triggered by the growing interest for ultra-endurance events in the middle-aged population (Knechtle et al. 2012; Stiefel et al. 2012). This has 
resulted in increased participation rates of the age group $>40$ years in sports events such as Ironman triathlon, marathon and $100 \mathrm{~km}$ ultra-marathon (Knechtle et al. 2012; Lepers and Cattagni 2012; Stiefel et al. 2012). Since a reasonable number of master athletes start exercising vigorously later in life and CV risk factors are already present (De Matos et al. 2011), it is essential to evaluate their CV risk profile.

There is clear evidence for structural remodeling (increase in arterial lumen size and decrease in wall thickness) of central arteries associated with endurance training (DeVan and Seals 2012; Green et al. 2012; SchmidtTrucksäss et al. 2000). Endurance athletes exhibit a more favorable vascular phenotype and higher central arterial compliance compared to their sedentary and/or recreationally active controls (DeVan and Seals 2012; Tanaka et al. 1998, 2000; Vaitkevicius et al. 1993). While the impact of endurance training on central arterial compliance is unequivocal among studies (DeVan and Seals 2012; Tanaka et al. 1998, 2000; Vaitkevicius et al. 1993), the influence on peripheral arteries is less consistent (Burr et al. 2013; Nualnim et al. 2011; Tanaka et al. 1998; Vlachopoulos et al. 2010b).

Arterial stiffness is a widely recognized surrogate marker for atherosclerotic changes of the vascular walls and associated with increased CV events and all-cause mortality (Laurent et al. 2006; Vlachopoulos et al. 2010a). Two recent studies, employing the principle of applanation tonometry, revealed higher arterial stiffness in marathon (Vlachopoulos et al. 2010b) and ultra-marathon runners (Burr et al. 2013). Consequently, the notion has been raised that long-term strenuous exercise may have a deleterious effect on the vascular system. However, it has to be stressed that the applied methods to determine arterial stiffness in the two previous studies are blood pressure (BP) dependent and may therefore introduce potential confounding (Burr et al. 2013; Vlachopoulos et al. 2010b). In the study by Vlachopoulos et al. (2010b), compared to control subjects, marathon runners had a significantly higher BP, and the difference in pulse wave velocity (PWV) disappeared after adjustment for BP. Recently, a new and BP-independent method was introduced to measure arterial stiffness (Shirai et al. 2006, 2011). The stiffness parameter called cardio-ankle vascular index (CAVI) has been shown to correlate with CV risk factors (Kubozono et al. 2007) and predicts severity of coronary atherosclerosis (Nakamura et al. 2008). Therefore, we aimed at assessing the impact of highvolume long-term endurance training on indices of arterial stiffness in marathon runners and ultra-endurance athletes using this BP-independent method. We hypothesized that recreational athletes, marathon runners and ultra-endurance athletes would exhibit no differences in the CAVI (primary endpoint).

\section{Methods}

Study design and participants

We recruited nonelite, male marathon runners by an open invitation letter as part of the Grand Prix of Bern, a 10-mile race in Switzerland with $>25,000$ participants. All athletes applied by electronic mail. We excluded subjects with hypertension (resting $\mathrm{BP}>140 / 90 \mathrm{mmHg}$ ), known hypercholesterinemia and those with a history of CV disease except episodes of palpitations or non sustained arrhythmias. Additionally, current smokers were excluded and pack-years of former smokers were assessed. Study participants were randomly selected and allocated to three pre-defined groups according to their former participations in competitions: group I (recreational athletes, $\leq 1$ marathon), group II (marathon runners, $>1$ marathon) and group III (ultra-endurance athletes, 78 and $100 \mathrm{~km}$ races, long-distance triathlons). Assessment included transthoracic echocardiography, 24-h ambulatory BP monitoring and measurement of arterial stiffness. Before the tests, subjects were asked to abstain from food and caffeine-containing substances ( $\geq 3 \mathrm{~h}$ ) and alcohol ( $\geq 24 \mathrm{~h}$ ), and they were told to refrain from vigorous exercise training for $24 \mathrm{~h}$ before the tests. A detailed flowchart about subject recruitment and measurements is represented in Fig. 1. All athletes provided written informed consent and the protocol was approved by the local ethics committee.

Anthropometry and hemodynamic measurements

Body mass was measured with light clothing to the nearest $0.1 \mathrm{~kg}$ using a digital-balanced scale and stature to the nearest $0.5 \mathrm{~cm}$ using a wall-mounted stadiometer. Body mass index (BMI) was calculated as body mass divided by stature squared $\left(\mathrm{kg} \mathrm{m}^{-2}\right)$. Body surface area was calculated using the DuBois formula (DuBois 1916). Resting BP was measured three to five times at the right arm after a 10-min rest in supine position using VaSera VS-1500N (Fukuda Denshi Co. Ltd, Tokyo, Japan). The first measurement was excluded and the mean of all other measurements was used for data analysis.

\section{Sports history}

A comprehensive questionnaire was used to ascertain personal and sports histories. Lifetime training hours were calculated using the formula: average endurance and strength training hours per week multiplied by $52 \mathrm{mul}$ tiplied by training year (Wilhelm et al. 2011). Furthermore, cumulative lifetime competitions were assessed and expressed as marathon equivalents: half marathon $\times 0.5$; 
Fig. 1 Flowchart about subject recruitment, selection and measurements

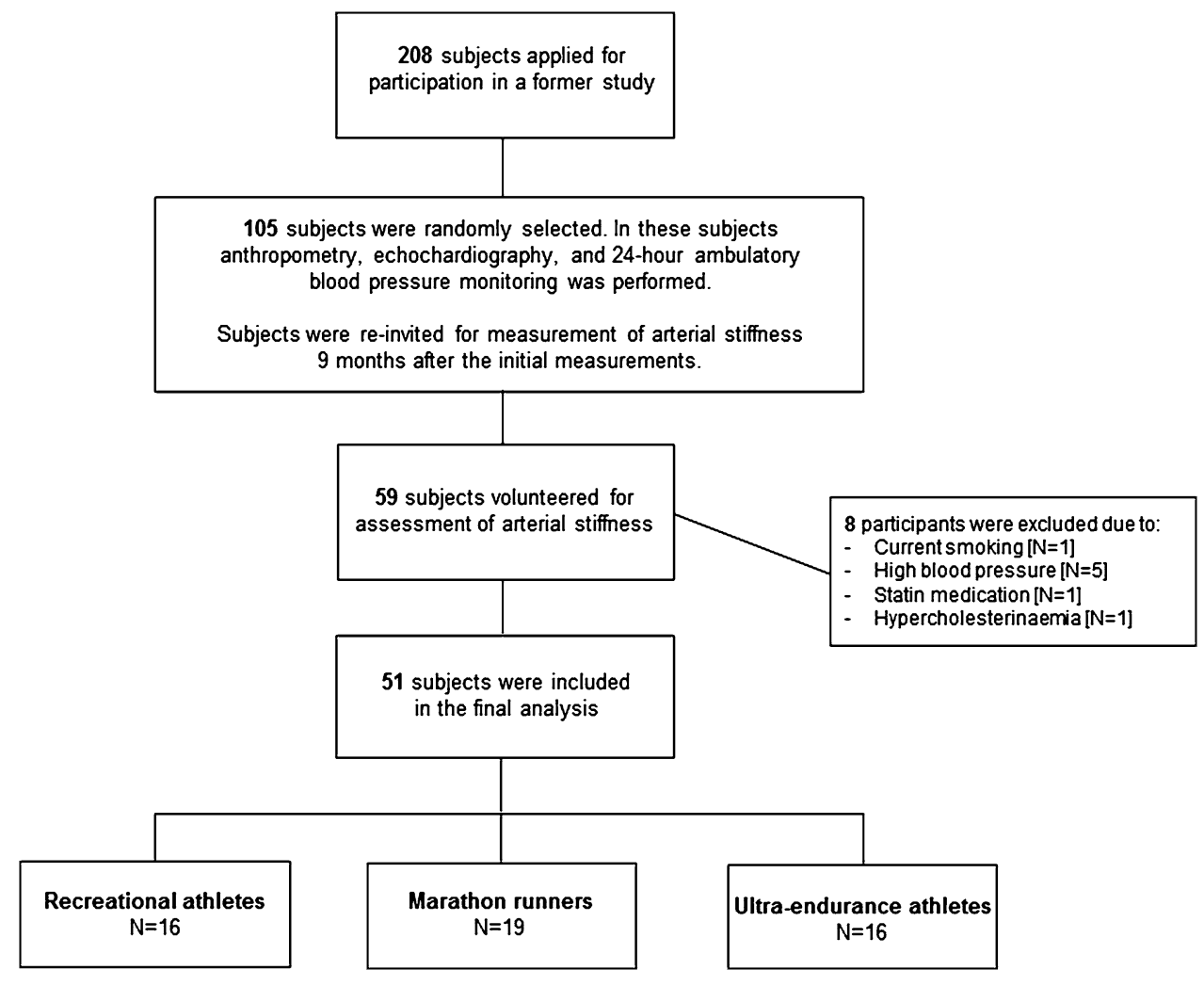

marathon $\times 1.0 ;$ mountain marathon $\times 1.2 ; 78 \mathrm{~km}$ race $\times 1.8$; Ironman triathlon race $\times 2.5$ and $100 \mathrm{~km}$ race $\times 2.5$.

\section{Arterial stiffness}

Arterial stiffness was measured in supine position using a non-invasive and BP-independent device (Shirai et al. 2011) (VaSera VS-1500N, Fukuda Denshi Co. Ltd, Tokyo, Japan). Measurements were performed between 15.00 and 18.00 p.m. to minimize the potential impact of diurnal variation in arterial stiffness. Details of this method can be found elsewhere (Shirai et al. 2006). In brief, subjects rested for at least $10 \mathrm{~min}$ in supine position before the first measurement. BP cuffs were placed around each arm and ankle and brachial pulse E-waves were detected at a low cuff pressure of $30-50 \mathrm{mmHg}$. A phonocardiogram was placed at the right sternal boarder in the second intercostal space. The CAVI is automatically calculated by the system and reflects the stiffness of the aorta, femoral artery and tibial artery. CAVI is determined by the following equation: CAVI $=a\left\{(2 \rho / \Delta P) \times \ln \left(P_{\mathrm{s}} / P_{\mathrm{d}}\right) \mathrm{PWV}^{2}\right\}+b$, where $P_{\mathrm{s}}$ and $P_{\mathrm{d}}$ are systolic and diastolic BP, PWV is the pulse wave velocity between heart and ankle, $\Delta P$ is $P_{\mathrm{s}}-P_{\mathrm{d}}, \rho$ is blood density, and $a$ and $b$ are constants. The equation is derived from the Bramwell-Hill's equation (Bramwell 1922) and the stiffness parameter $\beta$ as defined in Hayashi et al. (1975). Reproducibility of the device has been demonstrated with a mean coefficient of variation of $3.8 \%$ (Shirai et al. 2006). CAVI was measured at least three times with 3-min time intervals in-between each measurement. The first CAVI measurement was performed to familiarize the subjects with the testing procedure and the result was not included in the analysis. In case of a difference greater than 0.3 in the CAVI between the second and third measurement, another one to two measurements were performed. We took the average of the left and right CAVI and used the mean of all measurements, excluding the first, for data analysis.

\section{4-h Ambulatory blood pressure}

Ambulatory BP monitoring was performed over a 24-h period using mobil-0-Graph $\mathrm{NG}^{\circledR}$ (IEM, Stolberg, Germany), a device that has recently been validated and recommended for clinical use (Wei et al. 2010). The monitor and the cuff (nondominant upper arm) was attached by a trained physician and a calibration reading was taken to ensure accurate readings. The device was programmed to measure BP every 15 min during the day and every $30 \mathrm{~min}$ during the night. BP data were stored in the monitor and then downloaded into device-specific computer software (Hypertension Management Software, Client Server, 4.5., IEM, Stolberg, Germany). Data were analyzed for the 
entire 24-h period and separately for daytime and nighttime. Subjects were allowed to perform exercise training at moderate intensities for $60 \mathrm{~min}$ on the day of the recording.

\section{Transthoracic echocardiography}

Standard transthoracic echocardiography was performed (X5-1, 1-5 MHz transducer, iE33, Phillips Healthcare, Zurich, Switzerland) according to recommendations of the European Association of Echocardiography (Evangelista et al. 2008). Images were stored digitally and analyzed off-line. Left ventricular (LV) mass, and end-diastolic and end-systolic volumes were calculated according to current recommendations and indexed for body surface area (Lang et al. 2006). LV ejection fraction was derived from enddiastolic and end-systolic volumes (Lang et al. 2006). Pulse wave Doppler was performed in the apical four-chamber view to obtain peak early filling (E-wave) and late diastolic filling (A-wave) velocities, and peak early filling/late diastolic filling velocity ratio. Pulse wave tissue Doppler imaging was performed in the apical four-chamber view to acquire peak septal mitral annular velocity $\left(e^{\prime}\right)$ (Nagueh et al. 2009). Reproducibility data on cardiac dimensions in an athletic population of our laboratory were published previously (Wilhelm et al. 2012a).

\section{Statistical analysis}

Statistical analyses were performed with SPSS for Windows (Version 17.0, SPSS Inc., Chicago, USA). The Kolmogorov-Smirnov test was used to check data for normal distribution. The $\chi^{2}$ test was performed to compare baseline categorical variables between groups. Normally distributed data were presented as mean \pm standard deviation (SD), and variables with skewed distribution were shown as median (inter-quartile range, IQR). Relations between variables were evaluated by simple regression analysis. Differences in anthropometric characteristics and training volume between the three groups were evaluated using analysis of variance (ANOVA) or Kruskal-Wallis tests, as appropriate. Analysis of covariance (ANCOVA) models were applied to detect differences in indices of arterial stiffness, echocardiographic, and 24-h BP data between groups including lifetime training hours as a covariate. We used linear regression models to determine predictors for CAVI and baPWV and adjusted for age, lifetime training hours and cumulative marathon equivalents and in the latter variable also for systolic BP. The level of significance was set at $\alpha=0.05$. Because there are no previous studies using CAVI and baPWV in endurance athletes upon which a power calculation could be based on, we included all volunteering subjects of the 105 invited participants of our previous study.

\section{Results}

For a related study (in preparation), 208 male athletes applied for participation and were classified according to the predefined groups. From each group, 35 athletes were selected by chance, and a total of 105 athletes were studied. The 105 subjects were re-invited to the present study and 59 volunteered to participate. Eight subjects had to be excluded due to reasons as listed in Fig. 1, resulting in 51 subjects who were included in the present study. There were no differences in anthropometric characteristics (Table 1) and resting BP between the three groups (Table 2). Echocardiographic findings revealed no differences in LV mass index, LV end-diastolic volume as well as systolic and diastolic function between groups (Table 2). Mean systolic BP during the 24-h recording and during nighttime was highest among ultra-endurance athletes $(P=0.009$ and $P=0.018$, respectively). The 10-mile race time significantly decreased from group I to III $(P=0.006)$. Moreover, compared to group I, median lifetime training hours and cumulative marathon equivalents were significantly higher in groups II and III, respectively, $(P<0.001)$. There was a tendency toward higher training volumes from group I to III in the past 3 months (Table 1).

\section{Arterial stiffness}

Cardio-ankle vascular index and baPWV were not different between groups I and III (see Table 3; Fig. 2). In linear regression analysis, age was the only independent predictor for CAVI $\left(R^{2}=0.239, \beta=0.455, P=0.001\right)$. Systolic BP was significantly associated with baPWV $\left(R^{2}=0.225\right.$, $\beta=0.403, P=0.004$, see Table 3). Simple linear regression analysis revealed no correlation between resting systolic BP and CAVI $\left(R^{2}=0.035, P=0.190\right)$. Systolic BP significantly correlated with baPWV $\left(R^{2}=0.164\right.$, $P=0.004)$.

\section{Discussion}

The main finding of the present study is that in normotensive subjects, a history of many years of very high training volume and large number of strenuous competitions, such as marathons and ultra-endurance races, were not associated with increased indices of arterial stiffness compared to recreational athletes.

In our study, measures of arterial stiffness (CAVI and baPWV) did not differ between ultra-endurance athletes, marathon runners and recreational athletes. This is in contrast to previous work (Burr et al. 2013; Vlachopoulos et al. 2010b). In the study by Vlachopoulos et al. (2010b), exercise volume (min day ${ }^{-1}$ ) was an independent 
Table 1 Baseline characteristics of the study population, stratified according to their participation in competitions

\begin{tabular}{|c|c|c|c|c|}
\hline Variable & $\begin{array}{l}\text { Recreational } \\
\text { athletes }(n=16)\end{array}$ & $\begin{array}{l}\text { Marathon } \\
\text { runners }(n=19)\end{array}$ & $\begin{array}{l}\text { Ultra-endurance } \\
\text { athletes }(n=16)\end{array}$ & $P$ value \\
\hline Age (years) & $41.0 \pm 6.9$ & $46.3 \pm 7.9$ & $45.9 \pm 9.7$ & 0.158 \\
\hline Height (cm) & $178.5 \pm 5.9$ & $176.5 \pm 5.6$ & $178.0 \pm 6.8$ & 0.590 \\
\hline Weight (kg) & $71.6(6.2)$ & $73.3(8.1)$ & $73.6(11.5)$ & 0.660 \\
\hline Body mass index $\left(\mathrm{kg} \mathrm{m}^{-2}\right)$ & $23.1 \pm 3.0$ & $23.3 \pm 1.4$ & $23.4 \pm 2.2$ & 0.926 \\
\hline Body surface area $\left(\mathrm{m}^{2}\right)$ & $1.9(0.1)$ & $1.9(0.2)$ & $1.9(0.1)$ & 0.589 \\
\hline Former smokers, $n(\%)$ & $4(25 \%)$ & $4(21.1 \%)$ & $6(37.5 \%)$ & 0.424 \\
\hline \multicolumn{5}{|l|}{ Training volume } \\
\hline Exercise training (years) & $8(14.3)$ & $17(20.0)$ & $15.5(12.3)$ & 0.072 \\
\hline ET last 3 months (h week ${ }^{-1}$ ) & $4.11 \pm 2.59$ & $5.11 \pm 2.30$ & $7.01 \pm 5.07$ & 0.093 \\
\hline ST last 3 months (h week ${ }^{-1}$ ) & $0.50 \pm 0.53$ & $0.35 \pm 0.33$ & $0.43 \pm 0.46$ & 0.619 \\
\hline Lifetime training $(\mathrm{h})$ & $1,508(2,119)$ & $3,804(2,548)$ & $4,890(5,353)$ & 0.008 \\
\hline \multicolumn{5}{|l|}{ Participation in competitions } \\
\hline Ultra-endurance races $(n)$ & - & - & $6.5(8)$ & $<0.001$ \\
\hline Mountain marathons $(n)$ & - & $1(3)$ & $2.5(6)$ & $<0.001$ \\
\hline Flat marathons $(n)$ & $0(1)$ & $3(7)$ & $5.5(9)$ & $<0.001$ \\
\hline Half marathons $(n)$ & $2.5(9)$ & $10(16)$ & $10(12)$ & 0.002 \\
\hline 10 -mile races $(n)$ & $5.5(8)$ & $10(11)$ & $15(20)$ & 0.042 \\
\hline Marathon equivalents $(n)$ & $5.1(4)$ & $15.8(19)$ & $31.4(31)$ & $<0.001$ \\
\hline \multicolumn{5}{|l|}{ Performance } \\
\hline 10-mile race time (h:min) & $1: 14 \pm 0: 09$ & $1: 08 \pm 0: 09$ & $1: 05 \pm 0: 07$ & 0.006 \\
\hline
\end{tabular}

Data are expressed as mean \pm standard deviation or median (inter-quartile range). ET endurance training, $S T$ strength training. Data were analyzed using ANOVA or Kruskal-Wallis tests, as appropriate. Lifetime training hours were calculated as time spent in endurance plus strength training exercises $\geq 18$ years of life)

determinant of increased arterial stiffness in marathon runners who trained on average $15 \mathrm{~h}$ week $^{-1}$ for a mean duration of 11 years. In that study, a higher carotid-femoral PWV was found in marathon runners compared to recreational athletes. However, BP was also significantly higher in the marathon group and, after adjustment for $\mathrm{BP}$, the differences in carotid-femoral PWV disappeared. We explicitly studied male, normotensive marathon runners and ultra-endurance athletes. Resting BP was well balanced between the groups, and hypertensive subjects ( $>140 / 90 \mathrm{mmHg}, n=5$ ) were excluded to avoid bias from the effect of BP on arterial stiffness. Nevertheless, ultraendurance athletes had significantly higher mean systolic BP values over the entire 24-h recording and during dayand nighttime $(8-9 \mathrm{mmHg}$ ), confirming that high-intensity activities may predispose to higher BP (Mark and Janssen 2008). In another study, Burr et al. (2013) found reduced large artery compliance in 18 ultra-marathon runners compared to physically active age-matched controls. No differences were observed for small artery compliance between the groups and significant relationships between years of ultra-marathon and small artery compliance disappeared after adjustment for age. Importantly, multiple linear regression analysis revealed no associations between training-related variables and either small or large artery compliance. Only in a small subgroup of runners $(n=9)$, for whom detailed training data were available, reduced arterial compliance was related to longer running distances per training session. The results, however, should be interpreted with caution due to the low sample size studied.

In normotensive middle-aged and older adults, Nualnim et al. (2011) observed a lower baPWV in runners and swimmers compared to sedentary control subjects, despite no changes in femoral artery compliance and femoral artery stiffness index. The lower baPWV appears to mirror the positive effects of endurance training on arterial compliance. Importantly, to eliminate potential deleterious effects of chronic physical inactivity on arterial compliance (Schmidt-Trucksäss et al. 1999; Tanaka et al. 2000), we chose a healthy and physically active control group that most likely reflects a healthy vascular compliance.

In our study, age was the only significant predictor for CAVI, and resting systolic BP was significantly associated with baPWV. This is in line with previous work showing that both, age and BP are the most powerful and independent predictors of aortic pulse wave velocity (Cecelja and Chowienczyk 2009). 
Table 2 Comparison between measures of arterial stiffness, echocardiography and 24-h ambulatory blood pressure monitoring data between marathon runners, ultra-endurance athletes and recreational athletes

\begin{tabular}{|c|c|c|c|c|c|}
\hline \multirow[t]{2}{*}{ Variable } & \multirow{2}{*}{$\begin{array}{l}\text { Recreational athletes } \\
(n=16)\end{array}$} & \multirow{2}{*}{$\begin{array}{l}\text { Marathon runners } \\
(n=19)\end{array}$} & \multirow{2}{*}{$\begin{array}{l}\text { Ultra-endurance } \\
\text { athletes }(n=16)\end{array}$} & \multicolumn{2}{|l|}{$P$ value } \\
\hline & & & & Unadjusted & Adjusted* \\
\hline \multicolumn{6}{|l|}{ Arterial stiffness } \\
\hline $\mathrm{HR}$ at rest (beats $\min ^{-1}$ ) & $54.6 \pm 8.7$ & $53.9 \pm 10.1$ & $55.0 \pm 7.9$ & 0.612 & 0.476 \\
\hline Systolic BP at rest $(\mathrm{mmHg})$ & $124.1 \pm 7.8$ & $122.2 \pm 8.0$ & $125.9 \pm 6.4$ & 0.303 & 0.333 \\
\hline Diastolic BP at rest $(\mathrm{mmHg})$ & $79.6 \pm 6.0$ & $78.9 \pm 5.9$ & $78.9 \pm 5.8$ & 0.895 & 0.941 \\
\hline CAVI & $6.78 \pm 0.6$ & $6.92 \pm 0.7$ & $6.76 \pm 0.8$ & 0.757 & 0.604 \\
\hline $\mathrm{baPWV}\left(\mathrm{m} \mathrm{s}^{-1}\right)$ & $11.12 \pm 1.1$ & $11.08 \pm 1.1$ & $10.98 \pm 1.2$ & 1.000 & 0.947 \\
\hline \multicolumn{6}{|l|}{ Echocardiography } \\
\hline LV mass index $\left(\mathrm{g} \mathrm{m}^{-2}\right)$ & $104.6 \pm 22.1$ & $100.8 \pm 20.6$ & $104.3 \pm 14.6$ & 0.745 & 0.913 \\
\hline LV end-diastolic volume (mL) & $114.6 \pm 21.1$ & $110.3 \pm 20.6$ & $116.6 \pm 17.4$ & 0.631 & 0.943 \\
\hline LV ejection fraction (\%) & $67.3 \pm 4.7$ & $64.6 \pm 5.8$ & $64.9 \pm 3.8$ & 0.254 & 0.379 \\
\hline $\mathrm{E} / \mathrm{A}$ ratio & $1.4(0.7)$ & $1.4(0.8)$ & $1.6(0.4)$ & 0.878 & 0.506 \\
\hline Peak $e^{\prime}\left(\mathrm{cm} \mathrm{s}^{-1}\right)$ & $12.3 \pm 2.3$ & $11.4 \pm 1.2$ & $11.7 \pm 1.9$ & 0.376 & 0.726 \\
\hline \multicolumn{6}{|l|}{ 24-h Ambulatory BP monitoring } \\
\hline Mean systolic BP (mmHg) & $121.1 \pm 7.2$ & $120.8 \pm 7.2$ & $128.9 \pm 9.8$ & 0.009 & 0.009 \\
\hline Mean diastolic BP (mmHg) & $79.1 \pm 5.9$ & $79.9 \pm 4.6$ & $81.6 \pm 5.4$ & 0.567 & 0.173 \\
\hline Mean systolic BP day (mmHg) & $123.7 \pm 8.1$ & $123.5 \pm 6.9$ & $131.9 \pm 10.7$ & 0.009 & 0.011 \\
\hline Mean diastolic BP day (mmHg) & $81.3 \pm 6.2$ & $82.2 \pm 4.7$ & $83.4 \pm 5.6$ & 0.537 & 0.150 \\
\hline Mean systolic BP night (mmHg) & $105.8 \pm 5.4$ & $107.0 \pm 9.9$ & $114.6 \pm 8.9$ & 0.009 & 0.018 \\
\hline Mean diastolic BP night $(\mathrm{mmHg})$ & $64.6 \pm 4.9$ & $67.9 \pm 6.4$ & $68.6 \pm 6.4$ & 0.139 & 0.236 \\
\hline Systolic dipping (\%) & $14.2 \pm 6.0$ & $13.4 \pm 5.2$ & $12.9 \pm 6.1$ & 0.810 & 0.949 \\
\hline
\end{tabular}

Data are expressed as mean \pm standard deviation or median (interquartile range). Data were analyzed using ANOVA or Kruskal-Wallis tests, as appropriate. $H R$ heart rate, $B P$ blood pressure, $C A V I$ cardio-ankle vascular index, $a b P W V$ brachial-ankle pulse wave velocity, $L V$ left ventricular, E/A ratio peak early filling/late diastolic filling velocity ratio, Peak $e^{\prime}$ peak septal mitral annular velocity

* Adjusted for lifetime training hours

Repetitive episodes of arterial shear stress are thought to be the main physiological stimulus evoking vascular adaptations through endothelium-dependent remodeling (Tinken et al. 2010). In particular, performing vigorous physical activities appears to prevent arterial stiffening in the general population (van de Laar et al. 2010), and according to our data, also in ultra-endurance athletes, which reflect a unique population performing intense and exhaustive exercise over decades. On the other hand, evidence from cross-sectional studies suggests that longterm strenuous exercise may indeed accelerate the atherosclerotic process (Möhlenkamp et al. 2008). In runners, the number of completed marathons was associated with coronary artery calcification in otherwise healthy subjects (Möhlenkamp et al. 2008). The underlying mechanisms for structural changes in vessels are multifactorial and not yet fully understood, but inflammatory processes, among others, appear to play a pivotal role. Vigorous exercise such as marathon running leads to an excessive release of circulating pro-inflammatory cytokines (Bernecker et al. 2013; Wilhelm et al. 2012b), oxidative stress (Knez et al. 2007) and production of vasoactive substances such as endothelin-1 (Otsuki et al. 2007) that may contribute to structural remodeling of small arteries, such as the coronary arteries, in the long term. Altogether, the controversial findings from different studies investigating arterial stiffness in athletes (Burr et al. 2013; Knez et al. 2008; Nualnim et al. 2011; Vlachopoulos et al. 2010b) may arise from different methodological approaches, e.g.: (a) different measurement methods to determine arterial stiffness; (b) single gender studies vs. mixed gender studies; (c) inclusion of athletes from different disciplines (runners, swimmers, triathletes) with different training histories and competition experience; (d) most importantly, the selection of different control groups (sedentary vs. active controls).

Some limitations need to be addressed in view of the present findings. Our results are based on a small and heterogeneous group of endurance-trained athletes. Based on the means and standard deviations (power $[1-\beta] 0.80$ and $\alpha=0.05$ ) of our study, a follow-up study verifying our findings would need $n=836$ and 15,456 to possess the power to detect a between-group difference in baPWV and 
Table 3 Independent predictors of arterial stiffness of study participants

Multiple linear regression analysis on CAVI and baPWV and adjusted for age, lifetime training hours, cumulative number of competitions and in the latter case also systolic blood pressure. CAVI cardioankle vascular index, $B P$ blood pressure, $b a P W V$ brachial-ankle pulse wave velocity

\begin{tabular}{lclcr}
\hline & Beta coefficient & Standard error $\beta$ & Standardized $\beta$ & $P$ value \\
\hline CAVI $\left(R^{2}=0.239\right)$ & & & & \\
Age & 0.037 & 0.011 & 0.455 & 0.001 \\
Lifetime training hours & 0.000 & 0.000 & 0.194 & 0.192 \\
Cumulative competitions & -0.007 & 0.005 & -0.210 & 0.162 \\
baPWV $\left(\mathrm{m} \mathrm{s}^{-1}\right)\left(R^{2}=0.225\right)$ & & & & \\
Age & 0.022 & 0.017 & 0.174 & 0.210 \\
Systolic BP & 0.059 & 0.020 & 0.403 & 0.004 \\
Lifetime training hours & 0.000 & 0.000 & 0.136 & 0.376 \\
Cumulative competitions & -0.012 & 0.008 & -0.226 & 0.144 \\
\hline
\end{tabular}

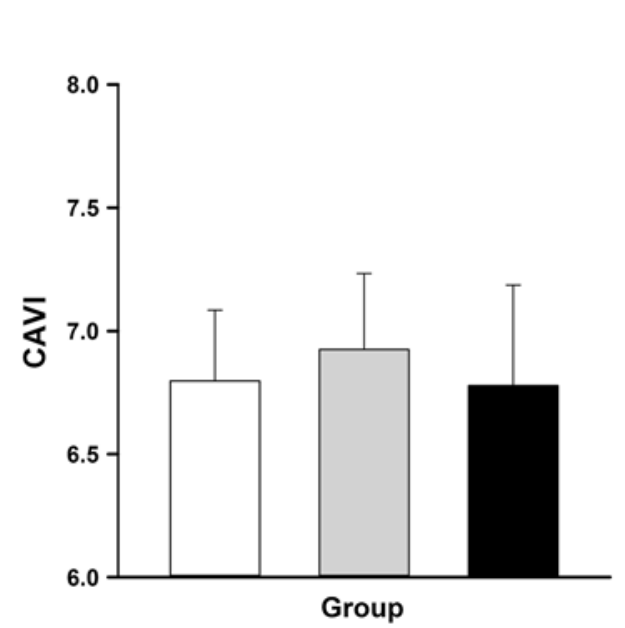

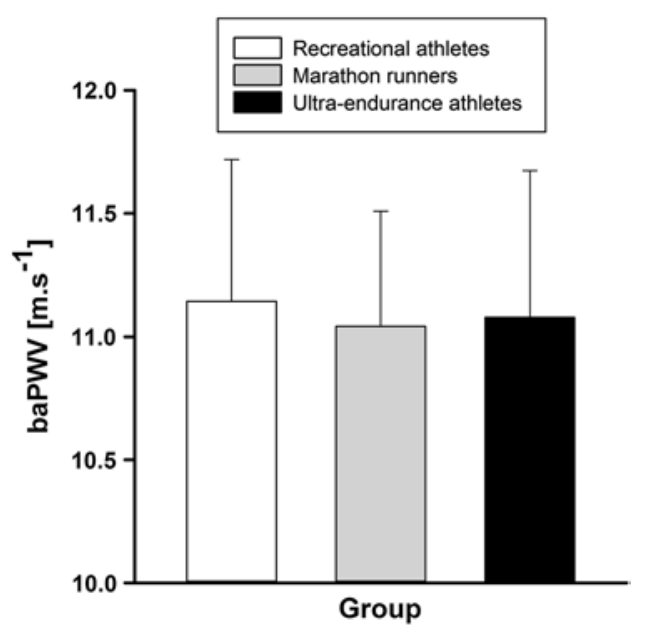

Fig. 2 Comparison of indices of arterial stiffness between ultra-endurance athletes, marathon runners and recreational athletes. There were no differences in CAVI or baPWV between groups. $b a P W V$ brachial-ankle pulse wave velocity, CAVI cardio-ankle vascular index
CAVI, respectively. This illustrates the minimal clinical relevance of the between-group differences in indices of arterial stiffness. This is further supported by the finding that an increase in brachial-ankle elasticity index by $1 \mathrm{~m} \mathrm{~s}^{-1}$ (compared to a $0.14 \mathrm{~m} \mathrm{~s}^{-1}$ difference between recreational and ultra-endurance athletes) corresponds to a $12 \%$ increase in total CV events (Vlachopoulos et al. 2012).

The calculation of the CAVI assumes blood viscosity to be constant across subjects. It has to be stressed that there is a large variability in blood viscosity among healthy subjects (Parkhurst et al. 2012) which could potentially influence arterial stiffness measurements. However, recent work by Parkhurst et al. (2012) revealed that whole blood viscosity does not significantly impact vascular function measures, including carotid-femoral PWV and carotid artery compliance in healthy subjects. Nevertheless, to which extent interindividual differences in blood viscosity impact on CAVI is currently unknown and could be a focus of future studies.

Based on the cross-sectional study design, we cannot establish causal relationships between training volume and indices of arterial stiffness. Moreover, arterial stiffness was measured 9 months after the initial assessment. CV risk factors may change over time and may potentially impact on arterial stiffness. To account for this, we reassessed CV risk factors, training history, anthropometric data and resting BP measurements at the second visit when arterial stiffness was assessed. Moreover, exclusion criteria were based on the second examination.

Our data suggest that even long-term participation in ultra-endurance sports has no negative impact on indices of peripheral arterial stiffness. Physiological adaptations of the vasculature to strenuous endurance exercise may result from positive stimuli, such as exercise-induced shear stress improving elastic properties of arteries as well as positive risk factor modification, on the one hand. However, on the other hand, long-term vigorous exercise may also lead to potentially deleterious mechanisms, such as inflammatory processes, vascular oxidative stress and mechanical fatigue of the elastic elements of vessels.

Acknowledgments We gratefully acknowledge the subjects' participation in this study. Moreover, we thank René Krause for athletes' recruitment, Yanlei Li for her technical instruction with the VaSera device and David Herzig for supporting us with the arterial stiffness measurements. We appreciate the intellectual input and critical review of the manuscript by Prisca Eser $(\mathrm{PhD})$.

Conflict of interest The authors have no conflicts of interest to report. 


\section{References}

Bernecker C, Scherr J, Schinner S, Braun S, Scherbaum WA, Halle M (2013) Evidence for an exercise induced increase of TNF-alpha and IL-6 in marathon runners. Scand J Med Sci Sports 23:207-214

Bramwell JCH, AV (1922) The velocity of the pulse wave in man. Proc R Soc Lond Ser B 93:298-306

Burr JF, Drury CT, Phillips AA, Ivey A, Ku J, Warburton DE (2013) Long-term ultra-marathon running and arterial compliance. J Sci Med Sport/Sports Med Aust. Epub ahead of print 22 May 2013. doi:10.1016/j.jsams.2013.04.018

Cecelja M, Chowienczyk P (2009) Dissociation of aortic pulse wave velocity with risk factors for cardiovascular disease other than hypertension: a systematic review. Hypertension 54:1328-1336

De Matos LD, Caldeira Nde A, Perlingeiro Pde S, dos Santos IL, Negrao CE, Azevedo LF (2011) Cardiovascular risk and clinical factors in athletes: 10 years of evaluation. Med Sci Sports Exerc 43:943-950

DeVan AE, Seals DR (2012) Vascular health in the ageing athlete. Exp Physiol 97:305-310

DuBois DD, EF (1916) A formula to estimate the approximate surface area if height and weight be known. Arch Int Med 17:863-871

Evangelista A, Flachskampf F, Lancellotti P, Badano L, Aguilar R, Monaghan M, Zamorano J, Nihoyannopoulos P (2008) European Association of Echocardiography recommendations for standardization of performance, digital storage and reporting of echocardiographic studies. Eur J Echocardiogr (J Work Gr Echocardiogr Eur Soc Cardiol) 9:438-448

Green DJ, Spence A, Rowley N, Thijssen DH, Naylor LH (2012) Vascular adaptation in athletes: is there an athlete's artery? Exp Physiol 97:295-304

Hayashi GSM, Niimi H, Handa H, Moritake K, Okumura A (1975) Analysis of vascular wall constitutive law with finite deformation theory. Med Electron Biol Eng 13:293-297

Knechtle B, Rust CA, Rosemann T, Lepers R (2012) Age-related changes in 100-km ultra-marathon running performance. Age (Dordr) 34:1033-1045

Knez WL, Jenkins DG, Coombes JS (2007) Oxidative stress in half and full ironman triathletes. Med Sci Sports Exerc 39:283-288

Knez WL, Sharman JE, Jenkins DG, Coombes JS (2008) Central hemodynamics in ultra-endurance athletes. J Sci Med Sport/ Sports Med Aus 11:390-395

Kubozono T, Miyata M, Ueyama K, Nagaki A, Otsuji Y, Kusano K, Kubozono O, Tei C (2007) Clinical significance and reproducibility of new arterial distensibility index. Circ J 71:89-94

Lang RM, Bierig M, Devereux RB, Flachskampf FA, Foster E, Pellikka PA, Picard MH, Roman MJ, Seward J, Shanewise J, Solomon S, Spencer KT, St John Sutton M, Stewart W (2006) Recommendations for chamber quantification. Eur J of Echocardiogr ( $\mathrm{J}$ Work Gr Echocardiogr Eur Soc Cardiol) 7:79-108

Laurent S, Cockcroft J, Van Bortel L, Boutouyrie P, Giannattasio C, Hayoz D, Pannier B, Vlachopoulos C, Wilkinson I, StruijkerBoudier H (2006) Expert consensus document on arterial stiffness: methodological issues and clinical applications. Eur Heart J 27:2588-2605

Lepers R, Cattagni T (2012) Do older athletes reach limits in their performance during marathon running? Age (Dordr) 34:773-781

Mark AE, Janssen I (2008) Dose-response relation between physical activity and blood pressure in youth. Med Sci Sports Exerc 40:1007-1012

Möhlenkamp S, Lehmann N, Breuckmann F, Brocker-Preuss M, Nassenstein K, Halle M, Budde T, Mann K, Barkhausen J, Heusch G, Jockel KH, Erbel R (2008) Running: the risk of coronary events : prevalence and prognostic relevance of coronary atherosclerosis in marathon runners. Eur Heart J 29:1903-1910
Nagueh SF, Appleton CP, Gillebert TC, Marino PN, Oh JK, Smiseth OA, Waggoner AD, Flachskampf FA, Pellikka PA, Evangelisa A (2009) Recommendations for the evaluation of left ventricular diastolic function by echocardiography. Eur J Echocardiogr ( $\mathrm{J}$ Work Gr Echocardiogr Eur Soc Cardiol) 10:165-193

Nakamura K, Tomaru T, Yamamura S, Miyashita Y, Shirai K, Noike $\mathrm{H}$ (2008) Cardio-ankle vascular index is a candidate predictor of atherosclerosis. Circ J 72:598-604

Nualnim N, Barnes JN, Tarumi T, Renzi CP, Tanaka H (2011) Comparison of central artery elasticity in swimmers, runners, and the sedentary. Am J Cardiol 107:783-787

O'Keefe JH, Lavie CJ (2013) Run for your life at a comfortable speed and not too far. Heart 99:516-519

O'Keefe JH, Patil HR, Lavie CJ, Magalski A, Vogel RA, McCullough PA (2012) Potential adverse cardiovascular effects from excessive endurance exercise. Mayo Clin Proc 87:587-595

O'Keefe JH, Schnohr P, Lavie CJ (2013) The dose of running that best confers longevity. Heart 99:588-590

Otsuki T, Maeda S, Iemitsu M, Saito Y, Tanimura Y, Ajisaka R, Miyauchi $T$ (2007) Vascular endothelium-derived factors and arterial stiffness in strength- and endurance-trained men. Am J Physiol Heart Circ Physiol 292:H786-H791

Parkhurst KL, Lin HF, Devan AE, Barnes JN, Tarumi T, Tanaka $\mathrm{H}$ (2012) Contribution of blood viscosity in the assessment of flow-mediated dilation and arterial stiffness. Vasc Med 17:231-234

Schmidt-Trucksäss AS, Grathwohl D, Frey I, Schmid A, Boragk R, Upmeier C, Keul J, Huonker M (1999) Relation of leisure-time physical activity to structural and functional arterial properties of the common carotid artery in male subjects. Atherosclerosis 145:107-114

Schmidt-Trucksäss A, Schmid A, Brunner C, Scherer N, Zach G, Keul J, Huonker M (2000) Arterial properties of the carotid and femoral artery in endurance-trained and paraplegic subjects. J Appl Physiol 89:1956-1963

Shirai K, Utino J, Otsuka K, Takata M (2006) A novel blood pressureindependent arterial wall stiffness parameter; cardio-ankle vascular index (CAVI). J Atheroscler Thromb 13:101-107

Shirai K, Song M, Suzuki J, Kurosu T, Oyama T, Nagayama D, Miyashita Y, Yamamura S, Takahashi M (2011) Contradictory effects of beta1- and alpha1- aderenergic receptor blockers on cardio-ankle vascular stiffness index (CAVI) - CAVI independent of blood pressure. J Atheroscler Thromb 18:49-55

Stiefel M, Knechtle B, Lepers R (2012) Master triathletes have not reached limits in their Ironman triathlon performance. Scand J Med Sci Sports. Epub ahead of print 14 May 2012. doi: 10.1111/j.1600-0838.2012.01473.x

Tanaka H, DeSouza CA, Seals DR (1998) Absence of age-related increase in central arterial stiffness in physically active women. Arterioscler Thromb Vasc Biol 18:127-132

Tanaka H, Dinenno FA, Monahan KD, Clevenger CM, DeSouza CA, Seals DR (2000) Aging, habitual exercise, and dynamic arterial compliance. Circulation 102:1270-1275

Thompson PD, Buchner D, Pina IL, Balady GJ, Williams MA, Marcus BH, Berra K, Blair SN, Costa F, Franklin B, Fletcher GF, Gordon NF, Pate RR, Rodriguez BL, Yancey AK, Wenger NK (2003) Exercise and physical activity in the prevention and treatment of atherosclerotic cardiovascular disease: a statement from the Council on Clinical Cardiology (Subcommittee on Exercise, Rehabilitation, and Prevention) and the Council on Nutrition, Physical Activity, and Metabolism (Subcommittee on Physical Activity). Circulation 107:3109-3116

Tinken TM, Thijssen DH, Hopkins N, Dawson EA, Cable NT, Green DJ (2010) Shear stress mediates endothelial adaptations to exercise training in humans. Hypertension 55:312-318 
Vaitkevicius PV, Fleg JL, Engel JH, O'Connor FC, Wright JG, Lakatta LE, Yin FC, Lakatta EG (1993) Effects of age and aerobic capacity on arterial stiffness in healthy adults. Circulation 88:1456-1462

van de Laar RJ, Ferreira I, van Mechelen W, Prins MH, Twisk JW, Stehouwer CD (2010) Lifetime vigorous but not light-to-moderate habitual physical activity impacts favorably on carotid stiffness in young adults: the Amsterdam Growth and Health Longitudinal Study. Hypertension 55:33-39

Vlachopoulos C, Aznaouridis K, Stefanadis C (2010a) Prediction of cardiovascular events and all-cause mortality with arterial stiffness: a systematic review and meta-analysis. J Am Coll Cardiol 55:1318-1327

Vlachopoulos C, Kardara D, Anastasakis A, Baou K, TerentesPrintzios D, Tousoulis D, Stefanadis C (2010b) Arterial stiffness and wave reflections in marathon runners. Am J Hypertens 23:974-979
Vlachopoulos C, Aznaouridis K, Terentes-Printzios D, Ioakeimidis N, Stefanadis C (2012) Prediction of cardiovascular events and allcause mortality with brachial-ankle elasticity index: a systematic review and meta-analysis. Hypertension 60:556-562

Wei W, Tolle M, Zidek W, van der Giet M (2010) Validation of the mobil-O-Graph: 24 h-blood pressure measurement device. Blood Press Monit 15:225-228

Wilhelm M, Roten L, Tanner H, Wilhelm I, Schmid JP, Saner H (2011) Atrial remodeling, autonomic tone, and lifetime training hours in nonelite athletes. Am J Cardiol 108:580-585

Wilhelm M, Roten L, Tanner H, Schmid JP, Wilhelm I, Saner H (2012a) Long-term cardiac remodeling and arrhythmias in nonelite marathon runners. Am J Cardiol 110:129-135

Wilhelm M, Zueger T, De Marchi S, Rimoldi SF, Brugger N, Steiner R, Stettler C, Nuoffer JM, Seiler C, Ith M. (2012b) Inflammation and atrial remodeling after a mountain marathon. Scand J Med Sci Sports. doi: $10.1111 / \mathrm{sms} .12030$ 